\title{
Kinetics of precipitation of gypsum and implications for pressure-solution creep
}

\author{
SIESE DE MEER, CHRISTOPHER J. SPIERS \& COLIN J. PEACH \\ High Pressure and Temperature Laboratory, Faculty of Earth Sciences, Utrecht University, PO Box 80.021, \\ 3508 TA Utrecht, The Netherlands (e-mail: S.deMeer@geo.uu.nl)
}

\begin{abstract}
In order to model the role of gypsum in crustal deformation and in trapping hydrocarbons, a quantitative, mechanism-based understanding of the deformation and compaction behaviour of gypsum is needed. Previous laboratory experiments indicate that intergranular pressure solution is an important deformation mechanism in gypsum and may be controlled by the kinetics of gypsum precipitation. To examine this further, the growth kinetics of gypsum were investigated using seed crystals and supersaturated aqueous solutions prepared from natural gypsum powders. The results showed both nucleation and growth dominated behaviour. Results relating purely to seed (over)growth showed that at low driving forces $(<1 \mathrm{~kJ} / \mathrm{mole})$ precipitation follows a second order growth law, while at larger driving forces the order is 3-4. The growth rates are 1 to 2 orders of magnitude slower than those reported in studies on pure systems. However, pressure-solution creep rates, predicted by coupling the present growth data with a microphysical model for pressure solution, are 1 to 2 orders of magnitude too fast to be consistent with experimentally obtained creep rates. On the other hand, the predicted and measured creep rates show an almost identical dependence on applied stress and grain size, supporting the hypothesis that pressure-solution creep in gypsum is controlled by the kinetics of precipitation.
\end{abstract}

Keywords: kinetics, gypsum, pressure solution, deformation, compaction.

On the basis of both field and laboratory studies, it is wellestablished that gypsum is one of the weakest and most ductile rock materials found in the Earth's crust (e.g. Heard \& Rubey 1966; Murrell \& Ismail 1976; Baumann 1984; Jordan 1988, 1991, 1994). In particular, gypsum-dominated evaporite sequences have long been recognized as playing an important role in controlling the strength of the Earth's upper crust through their action as weak décollement horizons, such as those characterizing the foreland thrust belts of the Alps or Pyrenees (e.g. Solé-Sugranes 1978; Davis \& Engelder 1985; Malavieille \& Ritz 1989; Jordan 1994). In addition, gypsumdominated evaporites frequently develop large scale 'halokinetic' structures such as pillows and diapirs (Wall et al. 1961; Gould \& De Mille 1968; Dabbagh et al. 1984; Doglioni 1984; Davis \& Engelder 1985; Van Berkel et al. 1986; Simón \& Suriano 1986; Underhill 1988; Kupfer 1989) which are sometimes associated with, or directly trap, large oil and gas accumulations (Balkwill 1978). Like rock salt, the characteristically low permeability of gypsum rocks and the high hydrocarbon sealing potential are, of course, determined by their low resistance to ductile flow and compaction.

For these reasons, considerable interest exists in obtaining a quantitative, mechanism-based description of the deformation and compaction behaviour of polycrystalline gypsum, suitable for numerical modelling studies of both crustal deformation and hydrocarbon migration/trapping phenomena. From a geotechnical viewpoint, data of this kind are also needed for modelling (i) the mechanical response of gypsum horizons present in the neighbourhood of evaporite-based waste repositories and storage caverns and (ii) the closure behaviour and stability of boreholes and wells sunk through gypsum sealing horizons.

During the last 30 years, numerous deformation experiments have been carried out on gypsum. These have shown that ductile flow of single crystals, and of gypsum rock deformed under nominally dry conditions (no added water), occurs primarily by intracrystalline dislocation mechanisms (Craker
\& Schiller 1962; Baumann 1984; Williams 1988; Nüesch \& Baumann 1989). Recently, however, compaction experiments performed by ourselves on sieved granular gypsum have shown that intergranular pressure solution becomes an important mechanism of time-dependent deformation (i.e. creep) when a saturated solution phase is added (De Meer \& Spiers 1995, 1997; see also Griggs 1939, 1940). Moreover, the results suggest that it is this mechanism that will dominate the flow and compaction behaviour of gypsum in nature (De Meer 1995). Accordingly, to arrive at a quantitative description of the deformation behaviour of gypsum under geological conditions, reliable data are needed on the kinetics of pressure solution in gypsum.

Intergranular pressure solution is perhaps most familiar as a mechanism of diagenetic compaction in sandstones (Rutter 1983; Tada \& Siever 1989). However, it is also an important mechanism of time-dependent deformation in both clastic and carbonate rocks under low-grade metamorphic conditions (Rutter 1983), and a principal mechanism of flow in rock salt during halokinesis (Spiers et al. 1990; Carter et al. 1993; Spiers \& Carter 1998). Under closed system, steady-state conditions, it involves dissolution of material within grain contacts under high mean normal stress, diffusion through an adsorbed intergranular fluid film or fluid-filled channel network, and precipitation at grain contacts or pore walls under low mean normal stress (Rutter 1976, 1983; Robin 1978; Tada et al. 1987; Lehner 1990, 1995; Spiers \& Schutjens 1990). These three transport steps are driven by stress-induced gradients in the chemical potential of the solid around grain surfaces, and, since they occur in series, the slowest controls the rate of transport and hence of creep (Raj 1982; Rutter 1983; Lehner 1990). Here, we will refer to the process as grain boundary diffusional pressuresolution creep. This term is chosen for consistency with our previous work and to draw a distinction with other classes of solution-transfer creep involving grain-scale plasticity coupled with irregular dissolution around grain-contact margins (see Spiers \& Brzesowsky 1993; De Meer \& Spiers 1995, 1997). 
In our previous experiments on pressure solution in gypsum, we compacted natural gypsum under both hydrostatic loading conditions (De Meer \& Spiers 1995) and uniaxially (De Meer $\&$ Spiers 1997). The experiments were conducted at constant applied stresses in the range $0.5-4.0 \mathrm{MPa}$, using samples with grain sizes in the range $30-300 \mu \mathrm{m}$. Whereas dry material exhibited no time-dependent deformation, samples flooded with saturated gypsum solution showed rapid compaction creep. The results were compared with microphysical models for pressure-solution creep, using literature data on the kinetics of gypsum dissolution and precipitation/growth as additional constraints. This led to the inference that compaction of the wet samples indeed occurred by the grain-boundary diffusional pressure-solution mechanism, and that precipitation of gypsum on pore walls was most likely the ratecontrolling step (De Meer \& Spiers 1995, 1997). However, despite broad agreement, several discrepancies between theory and experiment were noted. In particular, the observed rates of pressure solution were 2-4 orders of magnitude slower than expected from existing data on gypsum precipitation kinetics in high purity systems. Furthermore, it was inferred by De Meer \& Spiers (1997) that the kinetics of gypsum precipitation would have to show an inverse dependence on grain size (i.e. growth seed size) in order to explain fully the reported pressure solution behaviour.

We have speculated (De Meer 1995; De Meer \& Spiers 1995 , 1997; De Meer et al. 1997) that the above-mentioned rate discrepancy between pressure solution and crystal growth in gypsum might be due to the effects of growth-inhibiting impurity species present in the natural gypsum used in our pressure-solution experiments. However, to explain satisfactorily pressure solution phenomena in gypsum and to arrive at a mechanism-based kinetic description, the rate discrepancy problem needs further investigation, as does any grain-size dependence of precipitation reaction rates in the granular gypsum used in our pressure-solution tests (i.e. of De Meer \& Spiers 1997).

In the present paper, we attempt to resolve these problems by reporting crystal-growth experiments performed using seed crystals and supersaturated aqueous solutions prepared from natural gypsum powders identical to those used in the wet compaction experiments documented by De Meer \& Spiers (1997). To provide essential background, the paper opens with a summary of previous studies of the kinetics of gypsum crystal growth. The new crystal-growth experiments carried out using natural gypsum are then described. These were performed using supersaturations or driving forces similar to the lower end of the range calculated for our pressure solution experiments (i.e. supersaturations of $S=10-80 \%$ ), and using gypsum grain size fractions in the range $c .30-300 \mu \mathrm{m}$ as seed crystals. Emphasis is placed on determining absolute reaction rates, the order of the reaction and the possible influence of seed crystal size. The results are combined with a theoretical model for precipitation controlled, grain-boundary diffusional pressure solution to predict rates of creep by this mechanism. Improved agreement is obtained with the pressure-solution data reported by De Meer \& Spiers (1997), supporting the notion of precipitation reaction control.

\section{Previous work on the kinetics of gypsum precipitation}

Gypsum precipitation is an unwelcome problem associated with many industrial processes. It is of particular importance in the desalination of sea water by evaporation techniques, in waste water treatment, in phosphoric acid production, and in off-shore oil recovery where sea water is used for wellstimulation. For these reasons, numerous investigations have been carried out on the crystallization of calcium sulphate dihydrate (gypsum), the kinetics of crystal growth, and the mechanisms of crystal growth.

In the kinetics experiments reported to date, the rate of precipitation from aqueous solution was measured as a function of time, either by (i) recording the change of electrical conductivity of the solution (McCartney \& Alexander 1958; Smith \& Alexander 1970; Van Rosmalen et al. 1981; Christoffersen et al. 1982; Nielsen 1986; Weijnen 1986), (ii) recording the change of concentration of calcium in solution using a Ca-selective electrode (Liu \& Nancollas 1970; Christoffersen et al. 1979; Kushnir 1980), (iii) in-situ microscopic observations (Liu \& Nancollas 1973a; Tadros \& Mayes 1979; Bosbach \& Rammensee 1994; Bosbach et al. 1996) or (iv) analysing aliquots of the filtered solution for calcium ions by EDTA (ethylenediaminetetraacetic acid) titration (Liu \& Nancollas 1973b, 1975; Nancollas et al. 1973; Packter 1974; Brandse et al. 1977; Barcelona \& Atwood 1978; Gill \& Nancollas 1980; Weijnen 1986). Several of these investigations have been done using spontaneous crystallization techniques, in which $\mathrm{Na}_{2} \mathrm{SO}_{4}$ or $\mathrm{NaNO}_{3}$ solution and $\mathrm{CaCl}_{2}$ solution were added drop-wise to a saturated $\mathrm{CaSO}_{4}$ solution (McCartney \& Alexander 1958; Smith \& Alexander 1970; Packter 1974; Gill \& Nancollas 1980; Cody \& Cody 1988, 1991). After an initial 'surge' of precipitation during which nucleation took place, gypsum crystals grew following a rate equation showing a second-order dependence of growth rate or velocity on supersaturation. An exception is the work of Packter (1974), who inferred that the crystallization rate was a fourth-order process.

However, most studies of gypsum precipitation kinetics have been performed by means of seeded growth. In these experiments, a constant mass or volume of gypsum crystals was added to a supersaturated $\mathrm{CaSO}_{4}$ solution, and the rates of precipitation measured as a function of time using the same techniques as mentioned above. The supersaturated solutions used in these experiments were prepared by (i) mixing a $\mathrm{Na}_{2} \mathrm{SO}_{4}$ solution with a $\mathrm{CaCl}_{2}$ solution (Liu \& Nancollas 1970 , 1973a, b, 1975; Smith \& Alexander 1970; Barcelona \& Atwood 1978; Tadros \& Mayes 1979; Kushnir 1980; Bosbach et al. 1996), (ii) mixing a $\mathrm{K}_{2} \mathrm{SO}_{4}$ or $\mathrm{Li}_{2} \mathrm{SO}_{4}$ solution with a $\mathrm{CaCl}_{2}$ solution (Kushnir 1980) or (iii) dissolving the more soluble hemihydrate (Nancollas et al. 1973; Brandse et al. 1977; Christoffersen et al. 1979, 1982; Van Rosmalen et al. 1981; Nielsen 1986; Weijnen 1986; Bosbach \& Rammensee 1994). The bulk of these studies were performed in order to investigate the effect of additives on the growth kinetics and morphology of gypsum crystals, with the aim of assessing whether unwanted precipitation of gypsum in industrial processes could be retarded or stopped completely. Through these experiments, a wide variety of polymers (inorganic), organic compounds, acids and especially phosphonates (e.g. (A)MDP (amino)-methane-biphosphonic acid, and HEDP (1-hydroxyethylidene-1,1-biphosphonic acid) have been found to decrease greatly or completely block the growth of gypsum (McCartney \& Alexander 1958; Smith \& Alexander 1970; Liu \& Nancollas 1973b, 1975; Barcelona \& Atwood 1978; Tadros \& Mayes 1979; Weijnen 1986). This effect is caused by preferential adsorption of the phosphonates at active growth sites (e.g. Weijnen 1986). On the other hand, the rate of crystallization is 
Table 1. BET-specific surface data, X-ray fluorescence (XRF) analyses, and thermo-gravimetric analyses (TGA; heated to $950^{\circ} \mathrm{C}$ at $1-50^{\circ} /$ minute depending on rate of weight loss) for the different seed-sizes used in the present growth experiments

\begin{tabular}{|c|c|c|c|c|c|}
\hline & c. $32 \mu \mathrm{m}$ & c. $48 \mu \mathrm{m}$ & c. $97 \mu \mathrm{m}$ & c. $160 \mu \mathrm{m}$ & c. $282 \mu \mathrm{m}$ \\
\hline Specific surface $\left(\mathrm{m}^{2} / \mathrm{g}\right)$ & 0.36 & 0.39 & 0.16 & 0.10 & 0.07 \\
\hline $\mathrm{H}_{2} \mathrm{O}$ (TGA) wt. $\%$ & 20.17 & 19.98 & 20.20 & 20.30 & 20.45 \\
\hline $\mathrm{SiO}_{2}$ wt. $\%$ & $<2.78$ & $<2.78$ & $<2.78$ & $<2.78$ & $<2.78$ \\
\hline $\mathrm{Al}_{2} \mathrm{O}_{3}$ wt. $\%$ & $<1.08$ & $<1.08$ & $<1.08$ & $<1.08$ & $<1.08$ \\
\hline $\mathrm{Fe}_{2} \mathrm{O}_{3}$ wt. $\%$ & $<0.92$ & $<0.92$ & $<0.92$ & $<0.92$ & $<0.92$ \\
\hline MnO wt. $\%$ & $<0.023$ & $<0.023$ & $<0.023$ & $<0.023$ & $<0.023$ \\
\hline MgO wt.\% & $<0.24$ & $<0.24$ & $<0.24$ & $<0.24$ & $<0.24$ \\
\hline $\mathrm{Na}_{2} \mathrm{O}$ wt. $\%$ & $<0.10$ & $<0.10$ & $<0.10$ & $<0.10$ & $<0.10$ \\
\hline $\mathrm{K}_{2} \mathrm{O}$ wt. $\%$ & $<0.10$ & $<0.10$ & $<0.10$ & $<0.10$ & $<0.10$ \\
\hline Sr ppm & 806.5 & 464.0 & 360.2 & 351.7 & 361.7 \\
\hline $\mathrm{TiO}_{2}$ wt. $\%$ & $<0.02$ & $<0.02$ & $<0.02$ & 0.02 & $<0.02$ \\
\hline $\mathrm{P}_{2} \mathrm{O}_{5}$ wt. $\%$ & 0.02 & $<0.02$ & $<0.02$ & 0.03 & $<0.02$ \\
\hline $\mathrm{Cl} \mathrm{ppm}$ & $<148.8$ & $<148.8$ & $<148.8$ & 357.3 & $<148.8$ \\
\hline $\mathrm{CaSO}_{4} \cdot 2 \mathrm{H}_{2} \mathrm{O}$ wt. $\%$ & 96.5 & 95.6 & 96.6 & 97.1 & 97.8 \\
\hline
\end{tabular}

The amount of gypsum present in each fraction was calculated using the loss of weight, due to dehydration of gypsum, determined by TGA analyses.

increased when $\mathrm{NaCl}, \mathrm{KCl}$ or $\mathrm{LiCl}$ are present in the solution due to the formation of complexed $(\mathrm{Na}, \mathrm{K}, \mathrm{Li}) \mathrm{SO}_{4}^{-}$ion pairs. These ion pairs make the otherwise strongly repelled sulphate more available to the negatively charged surfaces of the gypsum crystal (Brandse et al. 1977; Kushnir 1980). Regardless of the presence or absence of additives, however, and regardless of the absolute rate of precipitation, most seeded growth studies (Liu \& Nancollas 1970, 1973a; Nancollas et al. 1973; Christoffersen et al. 1979, 1982; Van Rosmalen et al. 1981; Nielsen 1986; Weijnen 1986) have yielded a second-order growth-rate description (i.e. a second-order relation between growth velocity and driving force or supersaturation) for most of the range of supersaturations investigated $(3 \% \leq \mathrm{S} \leq 200 \%)$. In a few cases where no additives were present (Liu \& Nancollas 1973a; Brandse et al. 1977; Christoffersen et al. 1982), the order of the kinetic relation was found to increase towards 3 or 4 at high supersaturations $(\mathrm{S} \geq 40-80 \%)$. Barcelona \& Atwood (1978) who performed their crystal growth experiments in natural sea water at supersaturations of $15-90 \%$, observed a third order rate dependence on supersaturation.

\section{Experiments}

\section{Approach}

The present experiments consisted of a series of seeded growth tests performed using natural gypsum seed crystals deposited in a supersaturated solution prepared from the same starting material. The experiments were carried out at room temperature using supersaturations up to a maximum attainable value of $80 \%$ or $S=0.8$. The supersaturation $S$ is defined henceforth as

$$
S=\frac{C-C_{\mathrm{o}}}{C_{\mathrm{o}}}
$$

where $C$ is the concentration of the supersaturated solution, and $C_{\mathrm{o}}$ is the (apparent) seed crystal solubility, determined at the end of each experimental run. The progress of the precipitation reaction (i.e. the changing concentration of solute), was monitored by measuring the change of electrical conductivity of the solution as a function of time. The grain size fraction used for the seed crystals was varied from experiment to experiment, so that any dependence of the precipitation rate on grain size could be systematically determined.

\section{Seed crystals and preparation of supersaturated solutions}

The seed crystals for the present experiments were taken from the same grain size batches as used for the uniaxial compaction creep experiments on wet granular gypsum aggregates reported by De Meer \& Spiers (1997). Grain size fractions with final average crystal sizes of approximately $32 \mu \mathrm{m}, 48 \mu \mathrm{m}, 97 \mu \mathrm{m}, 160 \mu \mathrm{m}$ and $282 \mu \mathrm{m}$ were used (standard deviation $\pm 23 \mu \mathrm{m}$ ). The specific surface area of the individual fractions was measured using $\mathrm{N}_{2}$ gas adsorption, i.e. using the technique developed by Brunauer, Emmett and Teller (BETtechnique). The BET results and chemical analysis data obtained for the different grain size fractions are given in Table 1 . Note that individual fractions were $96.5-98.6 \%$ pure $\mathrm{CaSO}_{4} \cdot 2 \mathrm{H}_{2} \mathrm{O}$. Washing of the various fractions using water, during preparation ensured that the content of highly soluble salts was below detection (Table 1).

Supersaturated solutions were made by dissolving the more soluble hemihydrate $\left(\mathrm{CaSO}_{4} \cdot{ }_{2}^{1} \mathrm{H}_{2} \mathrm{O}\right)$, prepared by dehydrating the natural gypsum starting material. To achieve this, the gypsum starting material (from the Paris Basin) was crushed in a Herzog disk mill to a grain size of approximately $2-5 \mu \mathrm{m}$ and subsequently dehydrated to the equivalent mass of hemihydrate (calculated assuming 100\% purity) by heating in an oven at $110^{\circ} \mathrm{C}$. The very fine-grained hemihydrate powder produced was then dissolved in doubly distilled water. Undissolved crystals in the supersaturated solution were filtered off using a vacuum filter system plus $0.4 \mu \mathrm{m}$ (Poretics) membrane filters. The process of dissolving and filtering the hemihydrate was repeated 5 times, to achieve the highest possible starting concentration of $\mathrm{CaSO}_{4}$ in solution $\left(C_{\text {init }} \leq 0.0244 \mathrm{M}\right)$.

\section{Experimental procedure}

The kinetics experiments performed are listed in Table 2 and were carried out using the apparatus illustrated in Fig. 1. The conductivity meter forming the central element of this system was a Knick digital conductometer with a resolution of $10 \mu \mathrm{S} \mathrm{cm} \mathrm{cm}^{-1}$, which is approximately equivalent to a concentration change of $8 \cdot 10^{-5} \mathrm{M}$. The temperature of the solution was measured with a type $\mathrm{K}$ (chromelalumel) thermocouple yielding a resolution of $0.1^{\circ} \mathrm{C}$. Both signals were logged using a 12-bit A/D converter situated in an Epson QX-16 microcomputer.

Before setting-up any individual experiment, the glass beaker, stirrer, thermocouple, and conductivity probe were first cleaned with Decon soap and thoroughly rinsed with distilled water. Careful decontamination is essential for meaningful conductivity measurements. The conductivity probe was then calibrated, using $0.01 \mathrm{M}$ to 
Table 2. Complete set of crystal-growth experiments reported

\begin{tabular}{lccccc}
\hline $\begin{array}{l}\text { Experiment/ } \\
\text { sample no. }\end{array}$ & $\begin{array}{c}\text { Approx. } \\
\text { grain size } \\
(\mu \mathrm{m})\end{array}$ & $\begin{array}{c}\text { Specific } \\
\text { surface } \\
\left(\mathrm{m}^{2} \mathrm{~g}^{-1}\right)\end{array}$ & $\begin{array}{c}\text { Initial conc. } \\
\mathrm{CaSO}_{4} \\
\left(\mathrm{mmole}^{-1}\right)\end{array}$ & $\begin{array}{c}\text { Initial } \\
\text { supersaturation }\end{array}$ & $\begin{array}{c}\text { Final conc. } \\
\mathrm{CaSO}_{4} \\
\left(\mathrm{mmole}^{-1}\right)\end{array}$ \\
\hline GY334G & 282 & 0.07 & 19.79 & 0.56 & 13.78 \\
GY335G & 48 & 0.39 & 24.42 & 0.80 & 13.71 \\
GY336G & 97 & 0.16 & 22.14 & 0.49 & 13.48 \\
GY337G & 160 & 0.10 & 18.01 & 0.33 & 12.52 \\
GY338G & 32 & 0.36 & 20.37 & 0.48 & 12.68 \\
\hline
\end{tabular}

$0.0001 \mathrm{M} \mathrm{CaSO}_{4}$ solutions, to obtain an experiment-specific conductivity v. concentration relation expressed as a linear best fit. The solutions were prepared by dissolving a calculated mass of the same natural gypsum as used for the growth experiments, assuming $100 \%$ purity. After re-cleaning the apparatus, $200 \mathrm{ml}$ of supersaturated solution was poured into the glass beaker, and the conductivity probe, thermocouple, and stirrer were immersed in the solution. The stirrer was then switched-on and adjusted to operate at a constant speed of approximately $200 \mathrm{rpm}$ (same for all experiments). Two grams of the chosen fraction of seed crystals, measured on an analytical balance (Mettler H10W, accuracy of $0.1 \mathrm{mg}$ ), were then added to the supersaturated solution, and the glass beaker was sealed with a plastic (parafilm) sheet to prevent evaporation. Immediately after addition of the seed crystals, logging of the conductivity and temperature signals was started and the progress of the precipitation reaction thus monitored.

Tests were terminated by measuring the temperature dependence of the final, asymptotic conductivity value (also used to determine $C_{\mathrm{o}}$ for each test). This was done by heating the beaker plus contents to $c .45^{\circ} \mathrm{C}$ and allowing it to cool down again to room temperature, after each experimental run. Accordingly, the raw conductivity data could be corrected for temperature-change effects. The crystals were finally filtered off using the vacuum filter system, dried at $40^{\circ} \mathrm{C}$ in air, and stored under dry conditions for subsequent study by scanning electron microscopy (SEM).

\section{Data processing}

The raw data files (conductivity, temperature, time records), obtained for each test, were first processed to correct the conductivity data to a

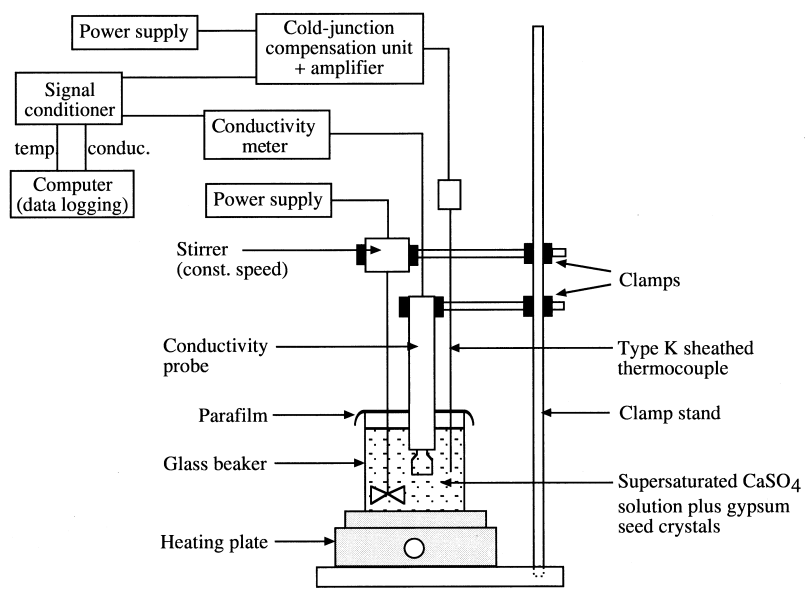

Fig. 1. Schematic diagram illustrating the conductivity measurement set-up used for the present crystal growth experiments on gypsum. The change of $\mathrm{CaSO}_{4}$ concentration in solution and the solution temperature were measured using a Knick digital conductometer and chromel-alumel thermocouple respectively. The corresponding signals were logged versus time using an Epson-QX16 microcomputer. constant reference temperature of $22^{\circ} \mathrm{C}$ (average temperature during the experimental runs). This was done using the dependence of conductivity on temperature (temperature calibration curve) determined at the end of each experiment. The test-specific conductivity calibration data were then used to calculate the $\mathrm{CaSO}_{4}$ concentration $(\mathrm{C}$ in mole/l) and supersaturation $(S)$ of the solution, the driving force for precipitation $(\Delta \mu)$, and the derivatives of $C$ and $S$ as a function of time, $t$. These quantities were computed assuming the starting materials to consist of pure $\mathrm{CaSO}_{4} \cdot 2 \mathrm{H}_{2} \mathrm{O}$. This is considered reasonable in view of the c. 95-98\% purity of the gypsum used and the extremely low soluble salt concentration. The driving force for precipitation was calculated using the dilute solutions relation (e.g. Christoffersen et al. 1979)

$$
\Delta \mu=R T \ln \frac{C}{C_{\mathrm{o}}}=R T \frac{C-C_{\mathrm{o}}}{C_{\mathrm{o}}}=R T S
$$

where, $R$ is the gas constant $\left(R=8.314 \mathrm{JK}^{-1} \mathrm{~mole}^{-1}\right)$, and $\mathrm{T}$ is the absolute temperature $(T=295 K)$. The concentration change (reduction) rate was obtained using

$$
\frac{\mathrm{d} C}{\mathrm{~d} t}=X \frac{\mathrm{d} \kappa}{\mathrm{d} t}
$$

where $X$ is the test-specific calibration coefficient linking concentration to conductivity, and $\mathrm{d} \kappa / \mathrm{dt}$ is the conductivity change rate), calculating the rate of change of conductivity $(\mathrm{d} \kappa / \mathrm{dt})$ as a function of time using a least squares fit method applied over a moving interval. The interval chosen was $50 \mu \mathrm{S} \mathrm{cm}^{-1}$, which is five times the resolution of the Knick conductometer. Conventional error analysis reveals that the total standard error in $\mathrm{d} \kappa / \mathrm{dt}$ ranges from $\pm 2 \%$ at the beginning of the experiments to $\pm 25 \%$ at the end of the experiments. Conductivity change rate data with errors $> \pm 10 \%$ were rejected.

\section{Results}

\section{Quantitative data}

A typical example of the conductivity data obtained is shown in Fig. 2. It shows that the conductivity and supersaturation dropped very fast at the start of the experiment, after which they asymptotically decreased to a more or less constant value. Corresponding log-log plots of concentration change rate $(\mathrm{d} C / \mathrm{d} t)$ versus driving force for precipitation are shown in Fig. 3. These show that for much of the driving force range investigated, the gypsum precipitation rate expressed as $\mathrm{d} C / \mathrm{d} t$ is proportional to the driving force squared (slope of 2 in Fig. 3), except for the c. $282 \mu \mathrm{m}$ seed crystals (Fig. 3b) where that $\mathrm{d} C / \mathrm{d} t$ is almost linearly proportional to the driving force (slope $=1)$. However, there is a tendency at high driving forces $(\log \Delta \mu>3)$ for the precipitation rate to be proportional to the driving force with a power greater than two. In addition, at the start of the experiments some clear differences can be observed 


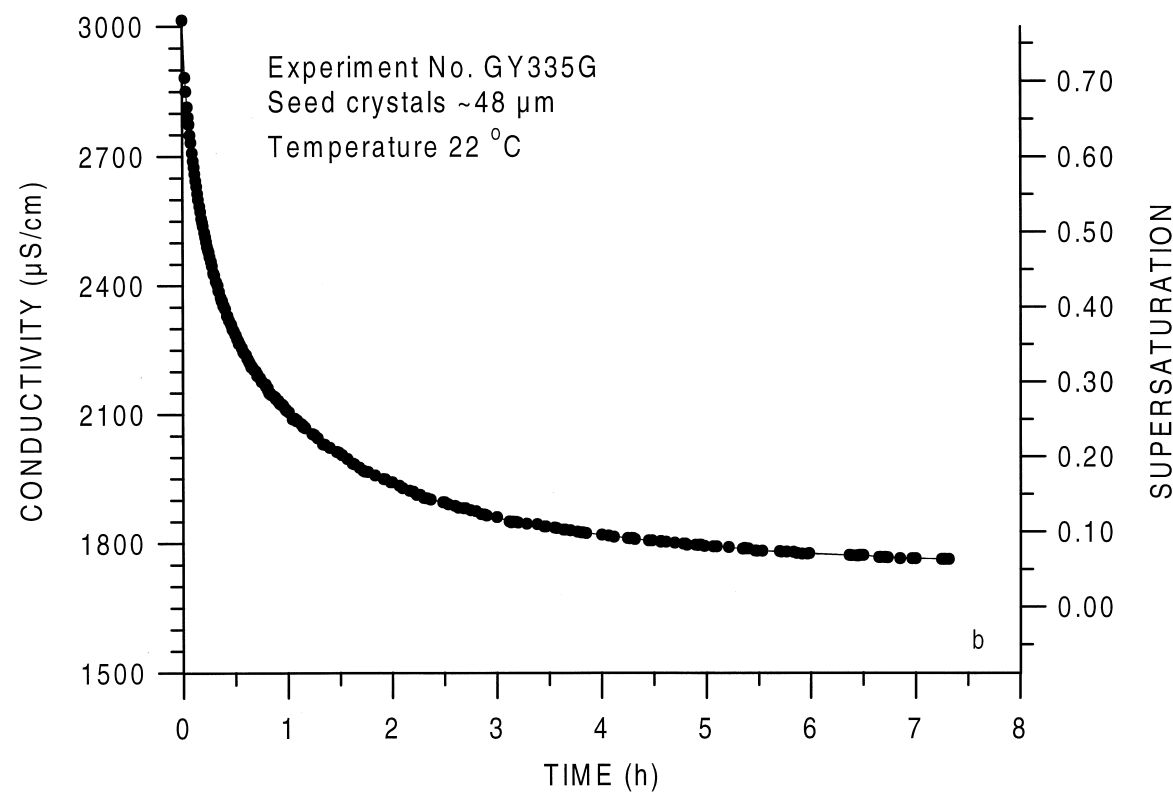

Fig. 2. Conductivity ( $\kappa)$, corrected to $22^{\circ} \mathrm{C}$, and supersaturation $(S)$ versus time data obtained for experiment using c. $48 \mu \mathrm{m}$ seed crystals.

between the different seed fractions (Fig. 3). For the smaller seed crystals used (c. $32 \mu \mathrm{m}$ and c. $48 \mu \mathrm{m}$; Fig. 3a), the precipitation rate $(\mathrm{d} C / \mathrm{d} t)$ started to decrease immediately from the beginning of the experiment, while for the larger seed crystals (c. $160 \mu \mathrm{m}$ and c. $282 \mu \mathrm{m}$; Fig. 3b) the quantity $\mathrm{d} C / \mathrm{d} t$ first increases before it starts to decrease. The data obtained from the experiment with c. $97 \mu \mathrm{m}$ seed crystals lies intermediate between these two trends. To illustrate any systematic grain size effects, Fig. 3 was used to construct a plot of concentration change rate $(\mathrm{d} C / \mathrm{d} t)$ versus grain size $(d)$ at constant driving force $(\Delta \mu)$; see Fig. 4. This shows that $\mathrm{d} C / \mathrm{d} t$ is roughly the same for all the seed-sizes used.

\section{SEM observations}

Both the starting seed crystals and final (dried) filtrate were studied using scanning electron microscopy (SEM). Figure 5 shows the $c .32 \mu \mathrm{m}$, and $c .282 \mu \mathrm{m}$ starting seed crystals, and the final products of the growth experiments performed using the c. $32 \mu \mathrm{m}, c .97 \mu \mathrm{m}$, and c. $282 \mu \mathrm{m}$ seed crystals. The c. $32 \mu \mathrm{m}$ starting seed crystals (Fig. 5a) have a subangular, non-uniform shape with many fines attached to their surfaces, while the c. $282 \mu \mathrm{m}$ starting seed crystals (Fig. 5b) are subrounded and have reasonably uniform shape with fewer fines attached to their surfaces. The intervening starting fractions were found to exhibit intermediate shapes and general appearance. In contrast, the final filtrate materials (Fig. 5c-e) are strikingly different from the starting material, though far from uniform from experiment to experiment. The experiments performed with the c. $32 \mu \mathrm{m}$ and c. $48 \mu \mathrm{m}$ seed crystals (test Nos GY338G and GY335G) show that the grains grew to become approximately euhedral (Fig. 5c). However, the material produced in the $c .97 \mu \mathrm{m}$ test (No. GY336G-Fig. 5d) shows that, besides euhedral growth of the seed crystals, nucleation and growth of fine acicular grains took place as well, at some stage of the experiment. This nucleation and growth is even more pronounced in the experiments performed using the $c .160 \mu \mathrm{m}$ and $c .282 \mu \mathrm{m}$ starting material (test Nos GY337G and GY334G), although there is also clear evidence for euhedral overgrowth on the seed crystals (Fig. 5e).

\section{Discussion}

\section{Growth rate versus rate of nucleation}

Focusing first on the SEM observations, it is believed that the heating of the solution plus contents at the end of each experiment to $45^{\circ} \mathrm{C}$, plus subsequent cooling to room temperature, did not influence the microstructure of the resulting material significantly, since the solubility of the gypsum in this temperature range changes by only $3 \%$. From the SEM images described above, it is thus inferred that, besides growth of the seed crystals during each experimental run, spontaneous nucleation from the solution also took place producing the fine acicular grains. This spontaneous nucleation was unimportant at 32 and $48 \mu \mathrm{m}$, but became more and more prominent, the larger the seed crystals used.

On this basis, the different trends observed in the plots of concentration change rate $(\mathrm{d} C / \mathrm{d} t)$ versus driving force $(\Delta \mu)$ presented in Fig. 3 are inferred to be related to varying amounts of spontaneous nucleation from solution. Thus, in the experiments done using the $c .32 \mu \mathrm{m}$ and $c .48 \mu \mathrm{m}$ seed crystals, little or no spontaneous nucleation occurred, and the steady decrease in supersaturation (i.e. driving force) observed in Fig. 3 is believed to be more or less entirely due to precipitation on the seed crystals. It is suggested that the initial increase in $\mathrm{d} C / \mathrm{d} t$ and subsequent decrease in $\mathrm{d} C / \mathrm{d} t$ with decreasing $\Delta \mu$, observed in the experiments using the larger grain-size fractions, is caused by spontaneous nucleation and subsequent precipitation on both the nuclei and seed crystals. Nucleation is presumably favoured in the coarser seed size experiments because the reduced seed surface area in these experiments makes seed growth less competitive.

From the above, it is clear that the mean seed or crystal overgrowth rate $\left(v_{\mathrm{p}}\right)$ can be calculated only for the $c .32 \mu \mathrm{m}$ and $c .48 \mu \mathrm{m}$ seed crystals. This precipitation rate was calculated as a function of driving force $(\Delta \mu)$, assuming that all 

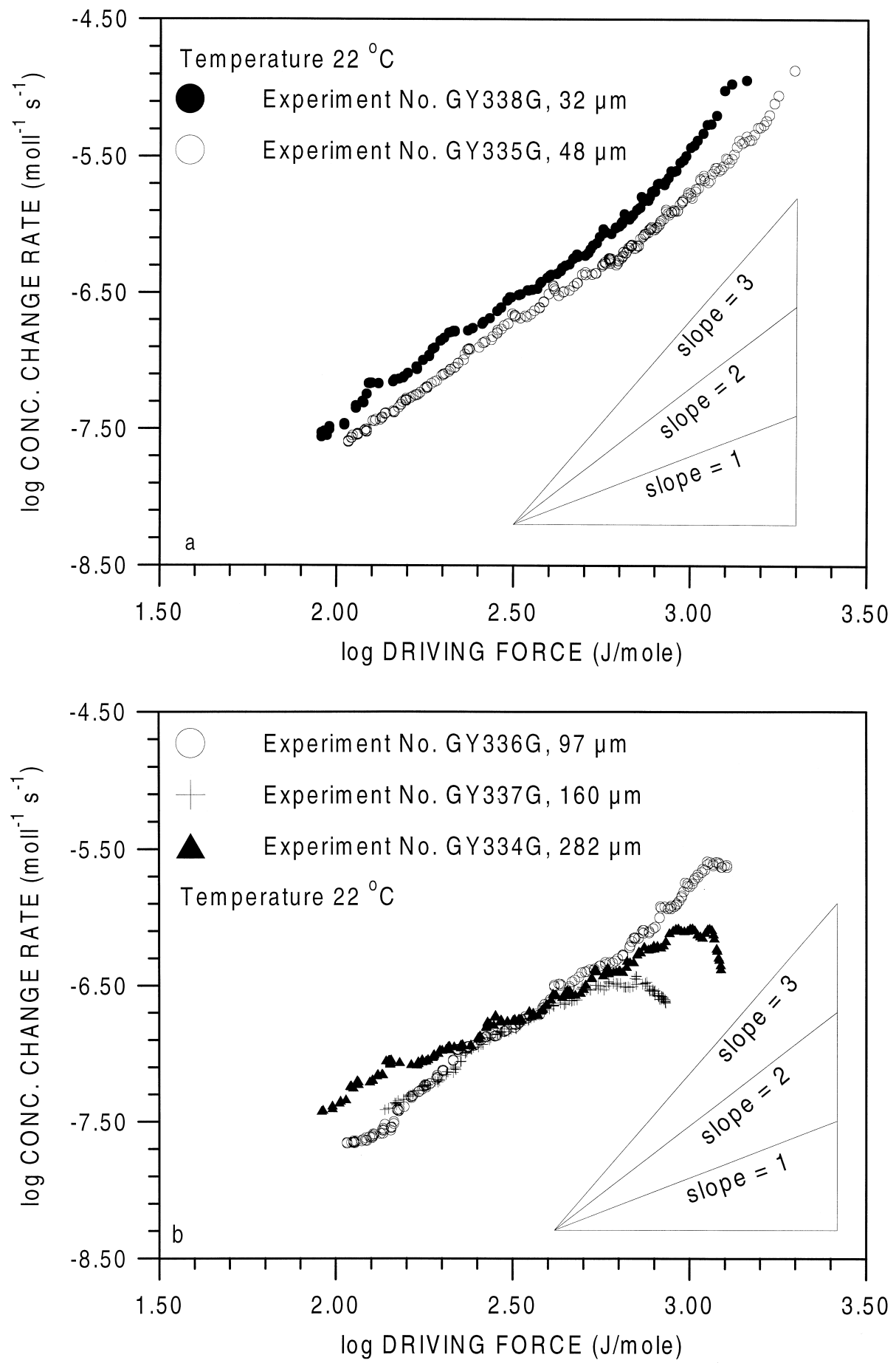

Fig. 3. $\log -\log$ plots of concentration change (drop) rate $(\mathrm{d} C / \mathrm{d} t)$ versus driving force $(\Delta \mu)$ for all seed sizes investigated; (a) c. $32 \mu \mathrm{m}$ and c. $48 \mu \mathrm{m}$ seed crystals, (b) c. $97 \mu \mathrm{m}, c .160 \mu \mathrm{m}$, and c. $282 \mu \mathrm{m}$ seed crystals. precipitation occurred on the seed crystals, using the equation (Nielsen \& Toft 1984)

$$
v_{\mathrm{p}}=\frac{\Omega_{\mathrm{s}}}{\mathrm{A}} \frac{\mathrm{d} n}{\mathrm{~d} t}=\frac{\Omega_{\mathrm{s}} V_{\text {liq }}}{A} \frac{\mathrm{d} C}{\mathrm{~d} t}
$$

where, is the molar volume of gypsum $\left(\Omega_{\mathrm{s}}=7.42 \cdot 10^{-5} \mathrm{~m}^{3}\right)$ mole), $\mathrm{A}$ is the specific surface of the seed crystals, $\mathrm{n}$ is the cumulative number of moles of material precipitated on the seeds, and $V_{\text {liq }}$ is the volume of solution used. The specific area (A) is assumed to be constant during the experiments, in view of the small mass of gypsum precipitated and the relatively large values of $\mathrm{A}$ in the experimental method employed. The $v_{\mathrm{p}}$ (calculated using A from Table 2) versus $\Delta \mu$ data thus obtained for the $c .32 \mu \mathrm{m}$ and $c .48 \mu \mathrm{m}$ seed crystals are presented in Fig. 6. Noting the log-log nature of this plot, the slopes of both the $32 \mu \mathrm{m}$ and $48 \mu \mathrm{m}$ curves show that the growth rate is roughly proportional to the driving force raised to the power $x=3-4$ in the region $\log \Delta \mu>3(\Delta \mu>1 \mathrm{~kJ} / \mathrm{mole})$, and raised to $x \approx 2$ in the region $\log \Delta \mu<3(\Delta \mu<1 \mathrm{~kJ} / \mathrm{mole})$. Figure 6 was also used to construct a plot of growth rate $\left(v_{\mathrm{p}}\right)$ versus grain size $(d)$ for fixed values of $\Delta \mu$ (Fig. 7). Though the data are minimal, this suggests an inverse first- to second-order dependence of growth rate on grain size for $\Delta \mu<1 \mathrm{~kJ} / \mathrm{mole}$, and an inverse second- to 


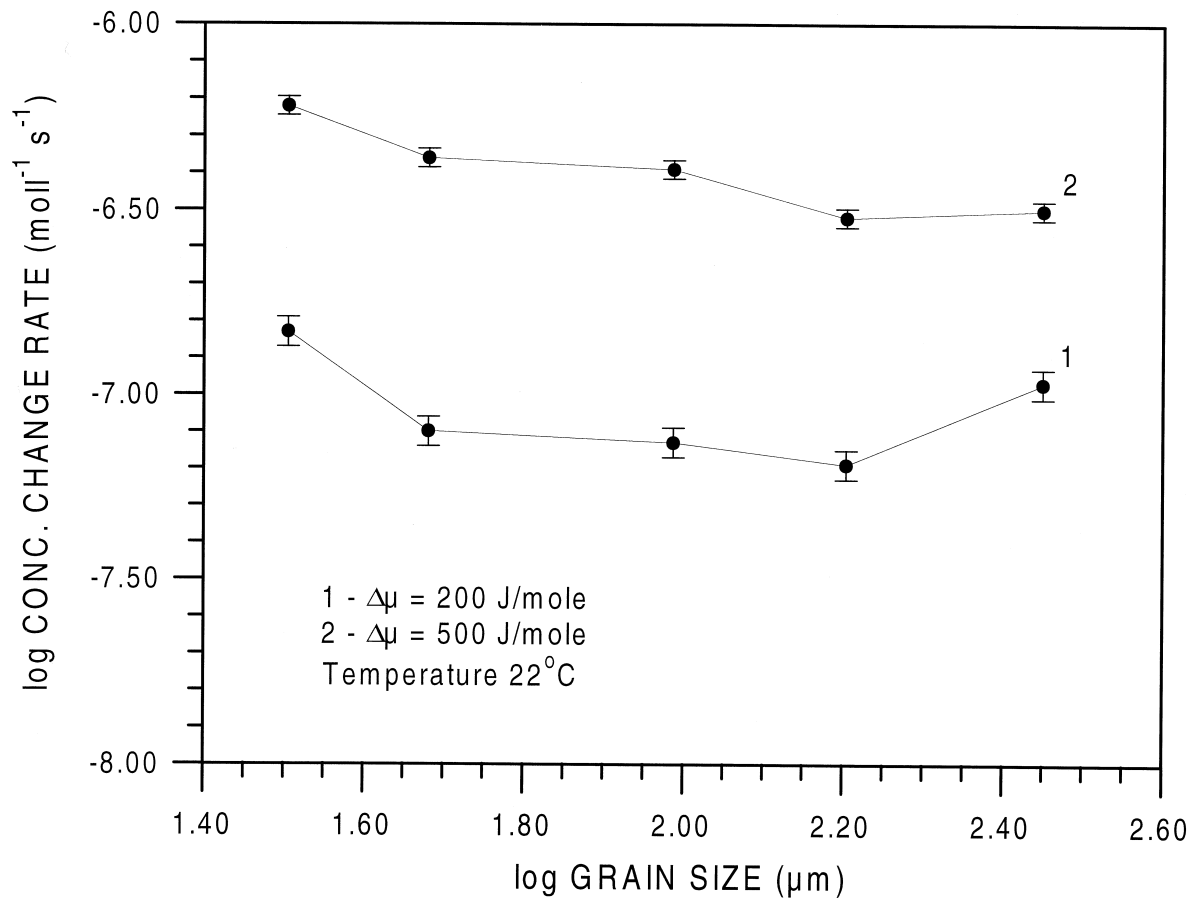

Fig. 4. $\log -\log$ plot of concentration change (drop) rate $(\mathrm{d} C / \mathrm{d} t)$ versus grain size $(d)$ for two different values of driving force $(\Delta \mu)$. Data displayed for all seed sizes investigated (i.e. all grain size fractions). third-order dependence of growth rate on grain size for $\Delta \mu>1 \mathrm{~kJ} / \mathrm{mole}$. The growth rate for the present experiments can thus be expressed empirically as

$$
v_{\mathrm{p}}=L_{1,2} \frac{(\Delta \mu)^{a}}{d^{b}}
$$

where $L_{1,2}$ are rate coefficients (constant at constant temperature), $a=2$ and $b=1-2$ at $\Delta \mu<c .1 \mathrm{~kJ} / \mathrm{mole}, a=3-4$ and $b=2-3$ at $\Delta \mu>c .1 \mathrm{~kJ} / \mathrm{mole}$. Note, however, that caution is needed with regard to the value of $b$, since data are available for only two grain sizes.

\section{Comparison with previous studies}

In Figs 6 and 7, the results of previous seed growth experiments, conducted under the same conditions (i.e. in $\mathrm{NaCl}$-free solutions) as those reported here (Brandse et al. 1977; Van Rosmalen et al. 1981; Christoffersen et al. 1982; Nielsen 1986; Weijnen 1986), have been combined with the results of the present study in a single plot of growth rate versus driving force (Fig. 6), and a plot of growth rate versus grain size at constant driving force (Fig. 7). Figure 6 shows that below a driving force of $c .1 \mathrm{~kJ} / \mathrm{mole}$, the growth rate is proportional to the driving force squared, implying second order growth kinetics, for all the different studies. This has previously been explained as being due to spiral growth at surface steps produced by screw dislocations (e.g. Christoffersen et al. 1982; Nielsen 1986; Sarig 1994). Above a driving force of $c .1 \mathrm{~kJ} /$ mole, the results of Brandse et al. (1977), Van Rosmalen et al. (1981) and the results of the present study show that the growth rate is approximately proportional to the driving force raised to the power 3 to 4 , implying third- to fourth-order growth kinetics. This type of behaviour has previously been explained by surface nucleation growth processes (e.g. Nielsen 1986; Sarig 1994). In addition, Fig. 7 shows that by combining the data of Brandse et al. (1977) and Nielsen (1986) for which the seed crystal sizes are accurately known, an approximately similar dependence of growth rate on grain size $\left(v_{\mathrm{p}} \alpha 1 / d^{c .1}\right)$ is indicated as for the present experiments at a low driving force $(\Delta \mu \approx 250 \mathrm{~J} / \mathrm{mole})$.

In addition to the above observations on the order of the growth kinetics, it can be seen from Figs 6 and 7 that the absolute rates of growth obtained in the present study, are about one order of magnitude slower than those obtained by the other authors cited, for comparable seed sizes. This is most probably a reflection of the use of natural gypsum as a starting material in the present study, whereas previous work used analytical reagents. The natural gypsum contains up to $5 \mathrm{wt} \%$ impurities, which, as mentioned already, mostly reduce the growth rate of gypsum (McCartney \& Alexander 1958; Smith \& Alexander 1970; Liu \& Nancollas 1973b, 1975; Barcelona \& Atwood 1978; Tadros \& Mayes 1979; Weijnen 1986). Significantly, the reduction in absolute growth rate seen in the present experiments, and in previous work on the effects of added impurities (Liu \& Nancollas 1970, 1973a; Nancollas et al., 1973; Christoffersen et al., 1979, 1982; Van Rosmalen 1981; Nielsen 1986; Weijnen 1986), does not effect the kinetic order of the growth reaction.

\section{Comparison with pressure solution experiments}

The growth kinetics data obtained in the present experiments will now be inserted into a theoretical model for compaction creep of porous aggregates by precipitation controlled grain boundary diffusional pressure-solution creep, thus predicting creep rates which can directly be compared to the pressuresolution creep data reported by De Meer \& Spiers (1997). Two extreme types of precipitation controlled pressure-solution creep models can be considered: one in which the rate of deformation is controlled by growth on the pore walls only (cf. seeded growth), and one in which the deformation is rate limited by nucleation and growth of crystallites forming in suspension in the pore fluid. Although the results obtained for the present experiments indicate that for the larger grain sizes 

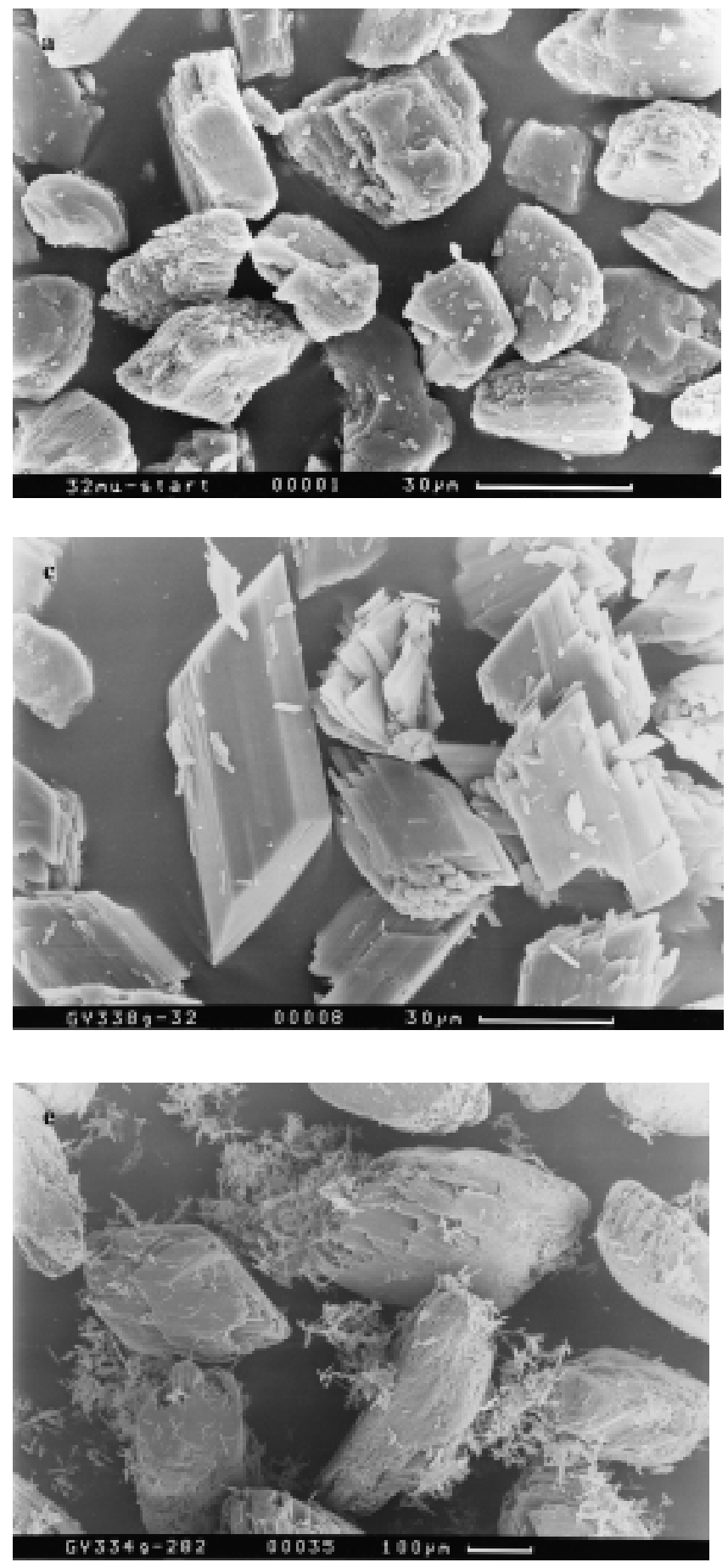

both growth and nucleation occur, no evidence was found for nucleation in the pressure solution experiments of De Meer \& Spiers (1997). This is thought to be a reflection of the ratio of the surface area of the granular solid phase $\left(A_{\mathrm{s}}\right)$ to the volume of liquid $\left(V_{\text {liq }}\right)$, which is very different for the two types of tests. The growth experiments yield a value for $A_{\mathrm{s}} / V_{\text {liq }}$ of $c .0 .7-$ $3.6 \mathrm{~m}^{-1}$, while in the pressure-solution experiments $A_{\mathrm{s}} / V_{\text {liq }}$ takes values in the range $150-800 \mathrm{~m}^{-1}$. Thus much more surface was available in the pressure-solution experiments than in the growth experiments, presumably leading to dominant growth rather than nucleation. On this basis, only the crystal growth data obtained for the $32 \mu \mathrm{m}$ and $48 \mu \mathrm{m}$ seed
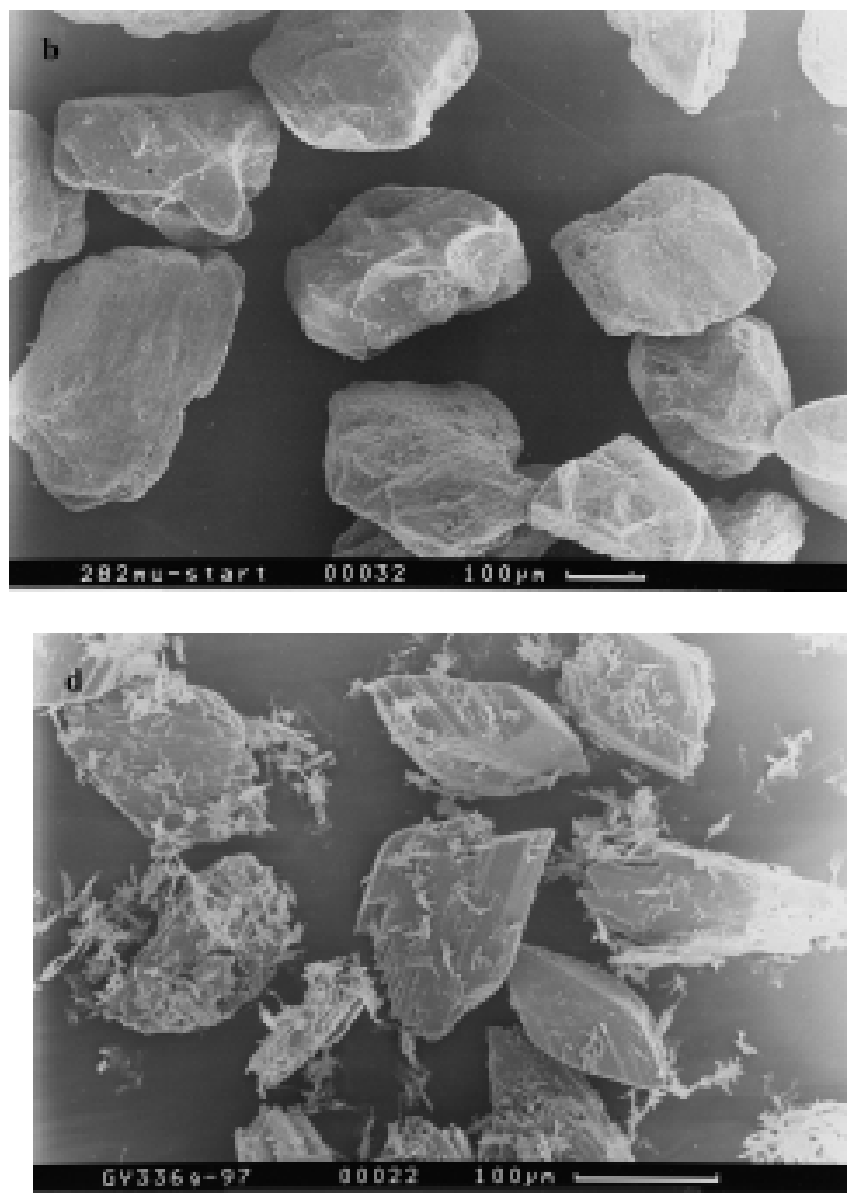

Fig. 5. Secondary electron images of the starting material $(a, b)$ and final filtrates (c-e). (a) Approximately $32 \mu \mathrm{m}$ starting seed crystals, and (b) c. $282 \mu \mathrm{m}$ starting seed crystals. Note the differences in shape, roundness and concentration of fines attached to the surfaces. (c-e) Final products obtained using c. $32 \mu \mathrm{m}$ (c), c. $97 \mu \mathrm{m}$ (d), and c. $282 \mu \mathrm{m}$ (e) seed crystals respectively (experiment nos GY338G, GY336G and GY334G). The approximately euhedral shape of gypsum crystals obtained in the experiments using the 32 and $48 \mu \mathrm{m}$ starting material is shown in (c). It can be seen in (d) that besides overgrowth of the seeds $(c .97 \mu \mathrm{m})$, small acicular crystals formed during the experiment. In the experiments using the 160 and $282 \mu \mathrm{m}$ starting material, the amount of small crystallites formed is very large, although there is also clear evidence for overgrowth on the seeds (e).

crystals will be used to predict pressure-solution creep rates, assuming rate limitation by growth on pore walls (seeded growth).

For precipitation controlled grain boundary diffusional pressure solution creep, it follows from theory (e.g. Raj 1982; Lehner 1990; De Meer \& Spiers 1995) that all the driving force is used to drive the precipitation step, with the driving force for dissolution and diffusion being negligibly small. The simple model used here (developed in more detail in De Meer \& Spiers 1999), applies to the case of uniaxial compaction by pore-wall growth controlled pressure solution, in an idealized aggregate consisting of a simple cubic pack of spherical grains (see 


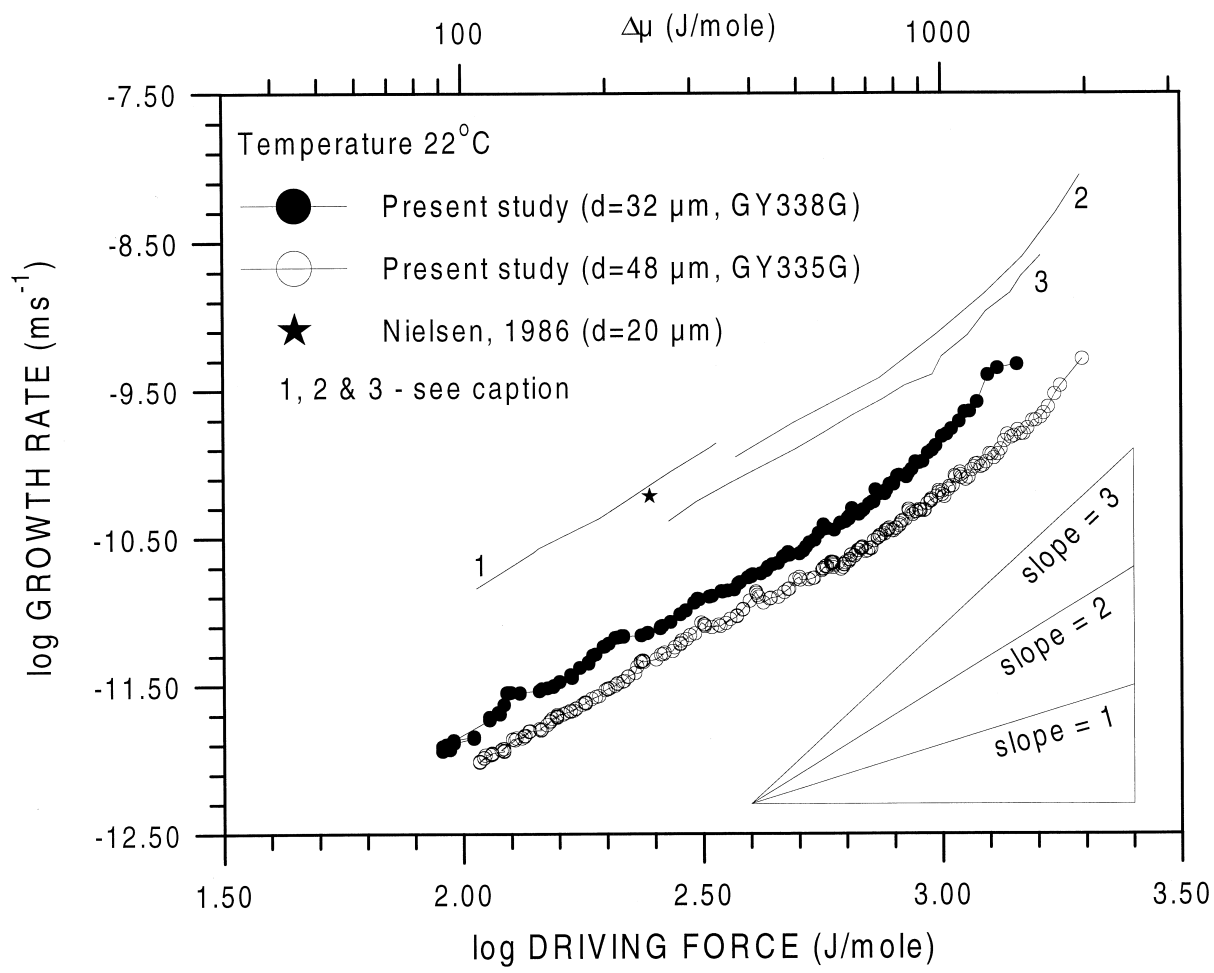

Fig. 6. Log- $\log$ plot of growth rate $\left(v_{\mathrm{g}}\right)$ versus driving force $(\Delta \mu)$ comparing the seed growth rate data obtained in the present study with growth rate data obtained by previous authors under similar experimental conditions (i.e in experiments using $\mathrm{NaCl}$-free solutions). 1. Christoffersen et al. (1982) and Weijnen (1986), $d=10-200 \mu \mathrm{m}$ but not accurately known. 2, Van Rosmalen et al. (1981), $d=$ not given. 3, Brandse et al. (1977), $d \approx 50 \mu \mathrm{m}$.
Fig. 8). In a granular aggregate of this type, the model can be written

$$
\dot{\varepsilon}=\frac{2 v_{\mathrm{p}}}{d} \frac{(1-Z)}{Z}
$$

or

$$
\dot{\varepsilon}=\frac{2 k_{a}^{+}(\Delta \mu)^{\mathrm{n}}}{d} \frac{(1-Z)}{Z}
$$

where $\dot{\varepsilon}$ is the strain rate, $v_{\mathrm{p}}$ is the growth velocity, $k_{a}^{+}$is the apparent precipitation reaction rate constant, $\Delta \mu$ is the driving force for precipitation, $\mathrm{n}$ is the order of the precipitation reaction, $d$ is grain size, and $Z$ is the ratio of contact area to total grain surface area $\left(Z=A_{\mathrm{d}} / A_{\mathrm{t}}\right)$. For a fixed value of compaction strain, hence $Z$, the driving force for precipitation is approximated (Rutter 1983; Lehner 1990; Spiers \& Brzesowsky 1993; Paterson 1995; Shimizu 1995) using the relation

$$
\Delta \mu=\left(\sigma_{\mathrm{n}}-P_{\mathrm{f}}\right) \Omega_{\mathrm{s}}
$$

where, $\sigma_{\mathrm{n}}$ is the average normal stress transmitted across dissolving grain contacts, $P_{\mathrm{f}}$ is the pore fluid pressure and $\Omega_{\mathrm{s}}$ is the molar volume of the solid. With increasing strain at constant applied stress $\left(\sigma_{\mathrm{a}}\right)$ and fluid pressure, $\sigma_{\mathrm{n}}$ decreases, and thus the driving force $\Delta \mu$ decreases as well. For the chosen idealized aggregate consisting of a cubic pack of spherical particles, the effective normal stress $\left(\sigma_{\mathrm{n}}-P_{\mathrm{f}}\right)$ is related to the applied effective stress $\sigma_{\mathrm{e}}=\left(\sigma_{\mathrm{a}}-P_{\mathrm{f}}\right)$ by the equation

$$
\sigma_{\mathrm{n}}-P_{\mathrm{f}}=\frac{\sigma_{\mathrm{e}} d^{2}}{Z A_{\mathrm{t}}} \approx \frac{\sigma_{\mathrm{e}}}{\pi Z} .
$$

For a compaction strain of $8-10 \%$ and corresponding value of c. 0.2 for the ratio of contact area to total area $(Z),\left(\sigma_{\mathrm{n}}-P_{\mathrm{f}}\right)$ thus takes a value of $\left(10 \sigma_{\mathrm{e}} / \pi\right)$. Inserting this into eq. 8 , for chosen stresses $\sigma_{\mathrm{a}}$, the resulting values for $\Delta \mu$ can be used to obtain corresponding values of $v_{\mathrm{p}}$ from Fig. 6 , which can in turn be inserted into eq. 6 to predict creep rates. Alternatively, creep rates can be predicted by directly inserting $\Delta \mu$ from 8 into eq. 7, together with the appropriate values for the apparent precipitation reaction rate constant $\left(k_{a}^{+}\right)$and the precipitation reaction order $(n)$ obtained from Fig. 6.

In Figs 9 and 10, the predicted pressure solution creep rates and experimentally obtained creep rates (De Meer \& Spiers 1997) are plotted versus applied effective stress $\sigma_{\mathrm{e}}=\left(\sigma_{\mathrm{a}}-P_{\mathrm{f}}\right)$ and grain size $(d)$ respectively. The sensitivity of creep rate to applied stress and grain size are found to be very similar: both experimentally obtained and predicted creep rates show a roughly second-order dependence of creep rate on applied stress, and suggests an inverse second- to third-order dependence on grain size. However, both figures also show that the predicted creep rates are roughly 30-50 times faster than the experimentally obtained creep rates. In view of the approximations and uncertainties associated with the present rough model for pressure solution (e.g. in estimating $Z$ ), this is considered to be reasonably good agreement, and is certainly an improvement compared with the 2-4-order difference obtained by De Meer \& Spiers (1997) using previous crystal growth data. The present findings thus support the notion that pressure solution in the gypsum studied is precipitation controlled. However, the remaining 1.5 order of magnitude difference in predicted and observed rates may have additional implications. One possibility is that the higher $A_{\mathrm{s}} / V_{\text {liq }}$ ratios characterizing our pressure solution experiments (De Meer \& Spiers 1997) may lead to higher impurity content in solution in the compaction tests than in the growth experiments, and hence to the lower than predicted strain rates. Otherwise, the substantial difference in creep rates might be explained by the fact that in the pressure solution experiments the grains are under stress, contrary to the growth experiments where the grains (i.e. seeds) are stress free. This could conceivably 


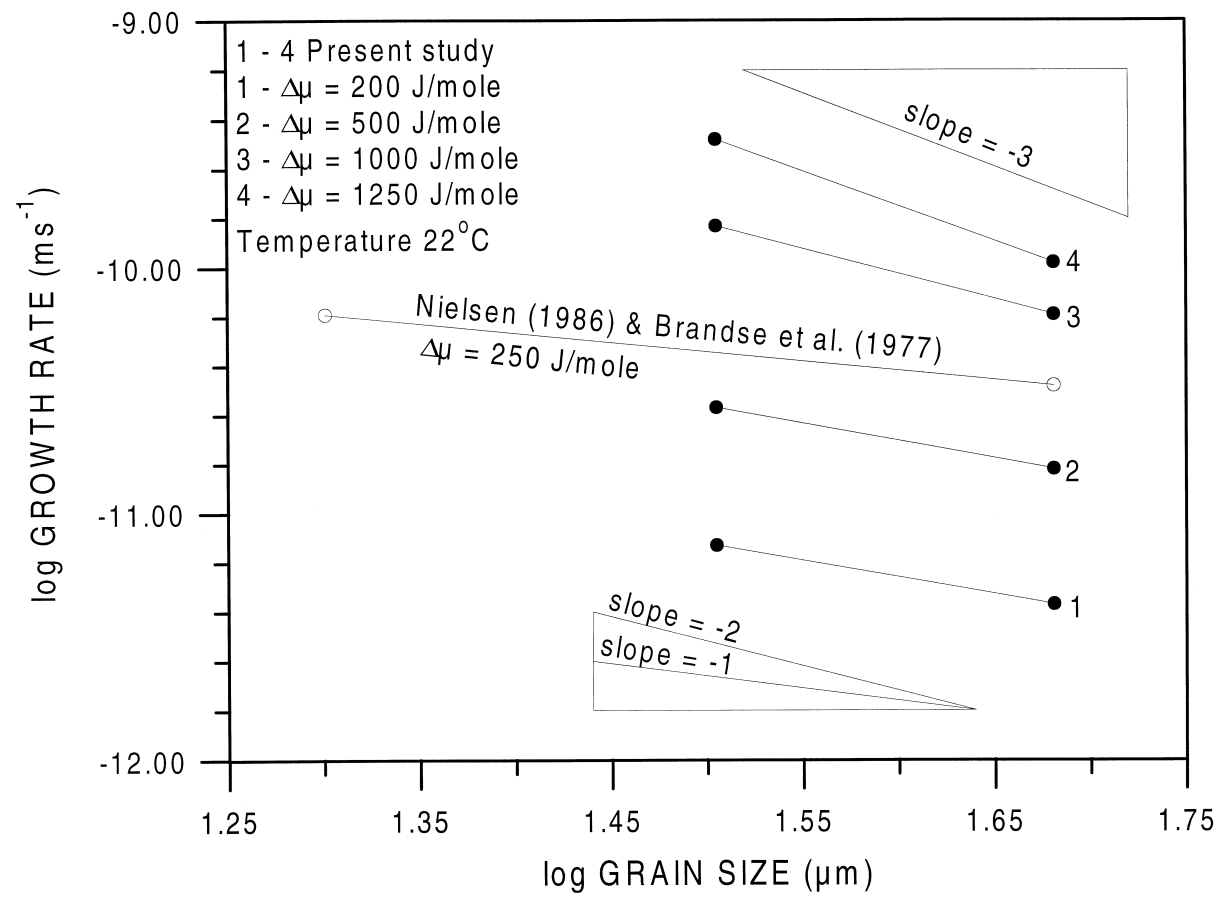

Fig. 7. Log-log plot of growth rate $\left(v_{\mathrm{g}}\right)$ versus grain size $(d)$ for four different values of driving force $(\Delta \mu)$ in the present experiments $(d=32$ and $48 \mu \mathrm{m}$-closed symbols), and for a driving force of $250 \mathrm{~J} / \mathrm{mole}$ for the combined data of Nielsen (1986; $d=20 \mu \mathrm{m})$ and Brandse et al. (1977; $d \approx 50 \mu \mathrm{m}$-open symbols). effect the growth mechanisms. As already pointed out, gypsum grows by spiral growth at steps produced by screw dislocations (second-order rate equation) at relatively low supersaturations $(S<40-80 \%$ - e.g. Van Rosmalen 1981; Christoffersen et al. 1982; Weijnen 1986), and probably by surface nucleation growth processes ( $>$ second order rate equation) at relatively high supersaturations $(S>40-80 \%$; e.g. Packter 1974; Christoffersen et al. 1982; Weijnen 1986). However, the extent to which these growth mechanisms might be affected by stressing the solid grains is beyond speculation at present.

In principle, a further possible explanation for the discrepancies between the present model predictions and experimental

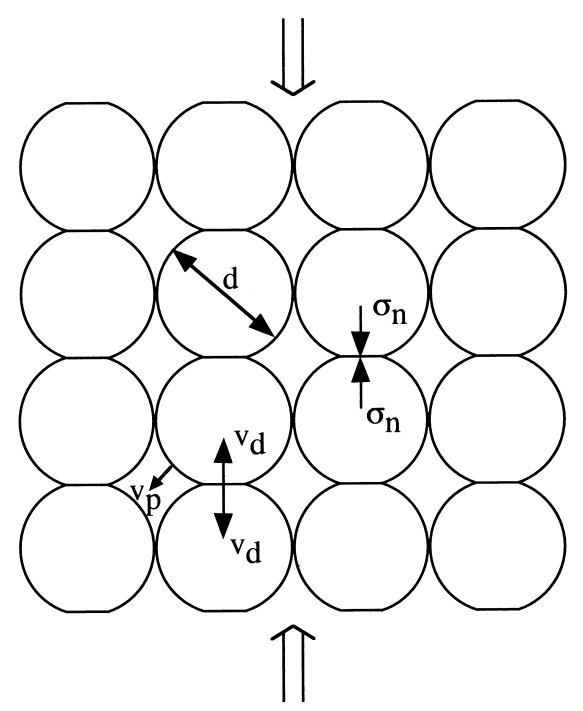

Fig. 8. Idealized aggregate (simple cubic pack of spherical grains) undergoing uniaxial compaction by grain boundary diffusional pressure solution, where $\sigma_{\mathrm{n}}$ is the normal stress across grain-to-grain contacts, and $v_{\mathrm{d}}$ and $v_{\mathrm{p}}$ are the velocities of dissolution and precipitation respectively. data, is that pressure solution may be diffusion controlled with stress dependent grain boundary transport properties. While this possibility cannot be completely eliminated, our previous compaction experiments involving through flow of solution saturated with respect to unstressed gypsum powder, provide evidence that this is not the case (De Meer \& Spiers 1997). It should be noted that the present interpretation of precipitation control applies to room temperature conditions. However, since the activation energy for grain boundary diffusion controlled pressure solution $(\Delta H \approx 20 \mathrm{~kJ} / \mathrm{mole}$; Nakashima 1995) is likely to be lower than for precipitation control $(\Delta \mathrm{H} \approx 63 \mathrm{~kJ} /$ mole for spiral growth; Liu \& Nancollas 1970, 1975), the possibility of a transition to diffusion control at elevated temperatures should be recognized.

\section{Conclusions}

In this paper, the growth of gypsum using seed crystals and solutions prepared from natural gypsum has been investigated in order (i) to determine the absolute rates of crystal growth, (ii) to determine the kinetic order of the precipitation reaction, (iii) to determine the dependence of growth rate on the size of the seed crystals, (iv) to predict pressure-solution creep rates using the obtained growth rates and (v) to compare the predicted rates with the creep rates observed in the pressure solution experiments reported by De Meer \& Spiers (1997). Due to spontaneous nucleation from the solution when using the large seed crystals $(d>48 \mu \mathrm{m}$, small specific surface area), the calculated growth rates of the large seed crystals are erroneous. The remaining results $(32 \mu \mathrm{m}$ and $48 \mu \mathrm{m}$ seed crystals) demonstrate that at low driving forces $(\Delta \mu<1 \mathrm{~kJ} /$ mole) precipitation on the seeds follows a second order growth law, while at higher driving forces $(\Delta \mu>1 \mathrm{~kJ} / \mathrm{mole})$ the order of the growth law is $3-4$, which is in good agreement with previously performed studies. Information on the dependence of growth rate on seed crystal size could only be obtained using the 32 and $48 \mu \mathrm{m}$ seed-size fractions. Nonetheless, the data suggest a roughly inverse first- to second-order dependence of 


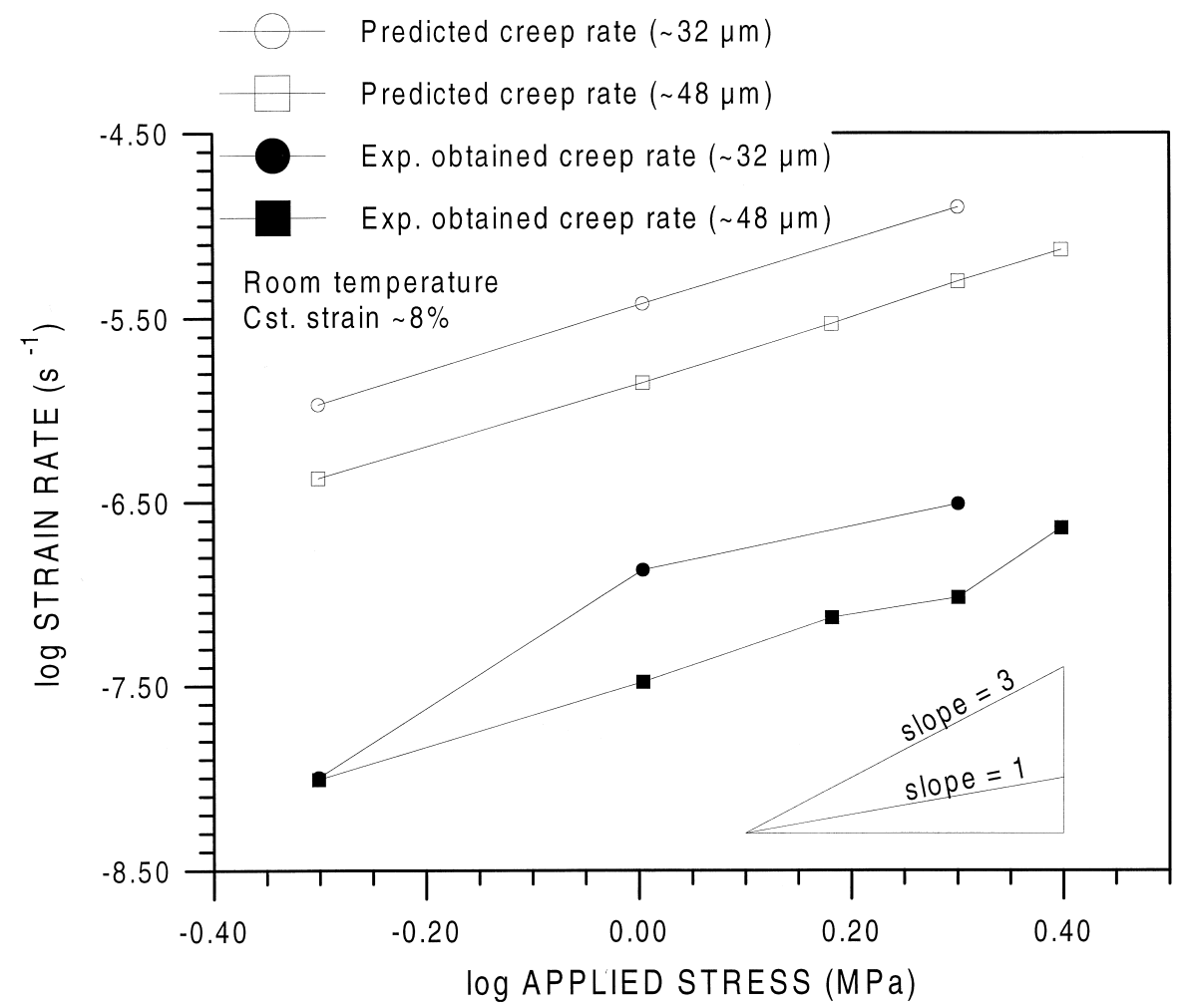

Closed symbols - exp. obtained creep rates

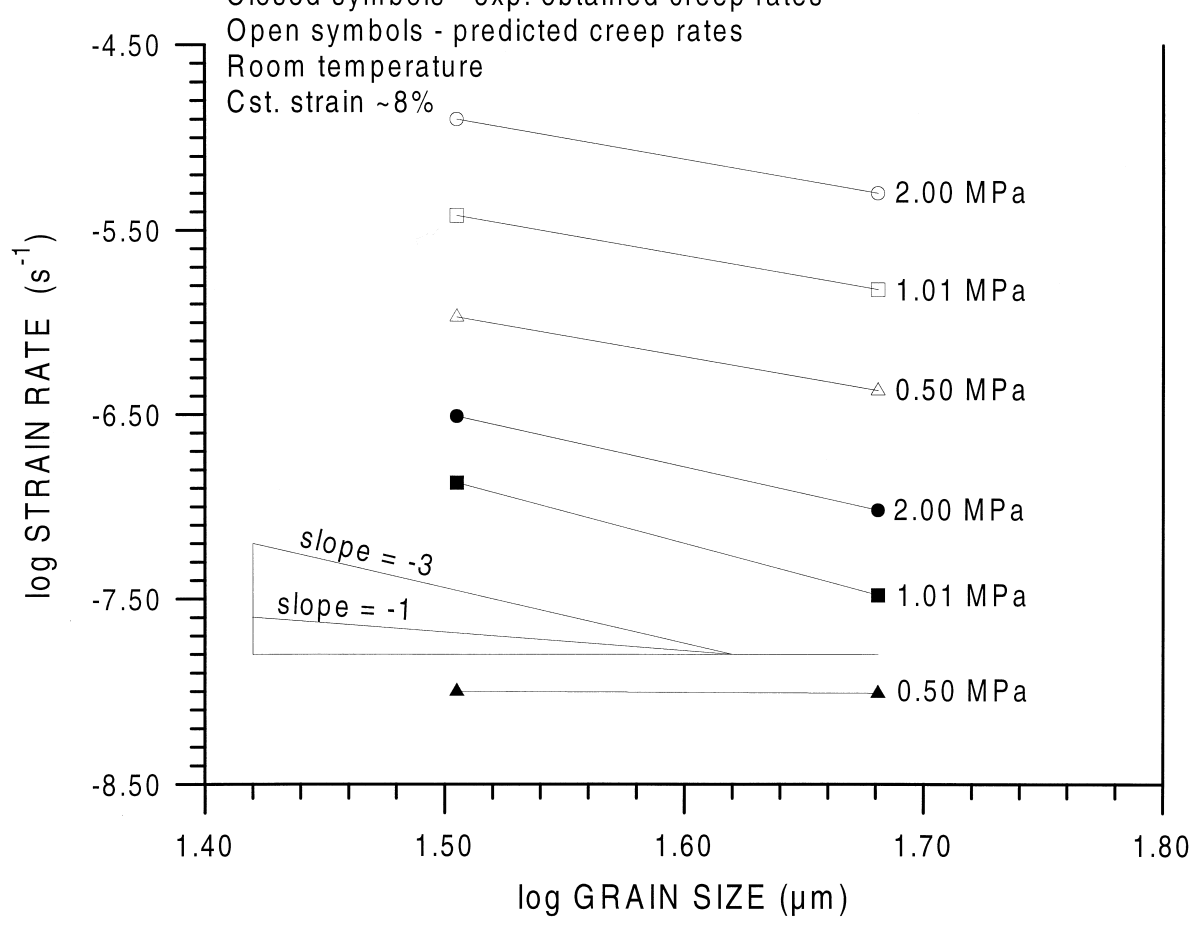

Fig. 9. $\log -\log$ plot of compaction strain rate versus applied effective stress $\left(\sigma_{\mathrm{e}}\right)$ showing experimentally obtained creep rates (De Meer \& Spiers 1997) and creep rates predicted by inserting the present crystal growth data into our model for precipitation controlled pressure solution.
Fig. 10. Log-log plot of compaction strain rate versus grain size $(d)$ showing experimentally obtained creep rates and creep rates (De Meer \& Spiers 1997) predicted by inserting the present crystal growth data into our model for precipitation controlled pressure solution. seed crystal size on growth rate at low driving forces $(\Delta \mu<1 \mathrm{~kJ} /$ mole), which is also reasonably consistent with previous data, and an inverse second- to third-order dependence of seed crystal size on growth rate at higher driving forces $(\Delta \mu>1 \mathrm{~kJ} /$ mole).

However, the absolute rates of crystal growth are found to be one order of magnitude lower than those obtained in previous work, which can most likely be attributed to the impurity content of the natural gypsum used. The obtained growth rates were used to predict grain boundary diffusional pressure solution creep rates with rate limitation by growth on pore walls (seeded growth). The predicted creep rates were found two be roughly 30-50 times faster than the creep rates observed in the pressure solution experiments performed by 
De Meer \& Spiers (1997) using the same gypsum starting material and grain-size fractions. However, the predicted creep rates and experimentally obtained creep rates show a closely similar dependence of creep rate on applied stress and grain size. It is therefore inferred that the pressure-solution process is most likely controlled by the precipitation reaction, with the absolute rate discrepancies probably reflecting the different solid/fluid ratios characterizing the pressure-solution and growth experiments. Clearly, however, additional kinetics work is still required for confirmation of this and to enable the development of a reliable constitutive model for the creep of gypsum by pressure solution. At present, the uncertainty regarding the rate controlling mechanism and limited kinetic data precludes the development of a mechanism-based creep equation for gypsum, with which reliable extrapolations to natural conditions can be made.

The authors thank P. van Krieken for general assistance in the laboratory. The research was supported by The Netherlands Organization for Applied Scientific Research (TNO Building and Construction Research) through EU Brite/Euram Project No. BE 3474. Comments by A. Maltman (editor) and reviewers E. Rutter and J.-P. Gratier led to significant improvements of the final version of this paper.

\section{References}

Balkwill, H.R. 1978. Evolution of Sverdrup basin, arctic Canada. American Association of Petroleum Geologists Bulletin, 62, 1004-1028.

Barcelona, M.J. \& ATWOOD, D.K. 1978. Gypsum-organic interactions in natural seawater: Effect of organics on precipitation kinetics and crystal morphology. Marine Chemistry, 6, 99-115.

Baumann, W. 1984. Rheologische Untersuchungen an Gips. Eclogae Geologica Helvetica, 77, 301-325.

Bosbach, D. \& Rammensee, W. 1994. In situ investigation of growth and dissolution on the (010) surface of gypsum by scanning force microscopy. Geochimica et Cosmochimica Acta, 58, 843-849.

— J Junta-Rosso, J.L., Becker, U. \& Hochella, M. 1996. Gypsum growth in the presence of background electrolytes studied by Scanning Force Microscopy. Geochimica et Cosmochimica Acta, 60, 3295-3304.

Brandse, W.P., Van Rosmalen, G.M. \& Brouwer, G. 1977. The influence of sodium chloride on the crystallization rate of gypsum. Journal of Inorganic and Nucleation Chemistry, 39, 2007-2010.

Carter, N.L., Horseman, S.T., Russell, J.E. \& Handin, J. 1993. Rheology of rocksalt. Journal of Structural Geology, 9, 1257-1271.

Christoffersen, J., Christoffersen, M.R., Van Rosmalen, G.M. \& Marchee, W.G.J. 1979. The affinity of crystal growth and dissolution in aqueous solution with special reference to calcium sulphate dihydrate. Journal of Crystal Growth, 47, 607-612.

, - Weijnen, M.P.C. \& Van Rosmalen, G.M. 1982. Crystal growth of calcium sulphate dihydrate at low supersaturations. Journal of Crystal Growth, 58, 585-595.

CoDy, A.M. \& CoDy, R.D. 1988. Gypsum nucleation and crystal morphology in analog saline terrestrial environments. Journal of Sedimentary Petrology, 58, 247-255.

\& - 1991. Chiral habit modifications of gypsum from epitaxial-like adsorption of stereospecific growth inhibitors. Journal of Crystal Growth, 113, 508-519.

Craker, W.E. \& Schiller, K.K. 1962. Plastic deformation of gypsum. Nature, 193, 672-673.

Dabbagh, A.E., Hoetzl, H. \& Schier, H. 1984. South Tihamah and Farasan Islands; Farasan Islands. Quaternary Period in Saudi Arabia, 2, 212-220.

DAvis, D.M. \& Engelder, T. 1985. The role of salt in fold-and-thrust belts. Tectonophysics, 119, 67-88.

DE MeER, S. 1995. Deformation processes in polycrystalline aggregates of gypsum. $\mathrm{PhD}$ dissertation, Utrecht University, Netherlands, and Geologica Ultraiectina, 132.

— \& SPIERS, C.J. 1995. Creep of wet gypsum aggregates under hydrostatic loading conditions. Tectonophysics, 245, 171-184.

\&_ 1997. Uniaxial compaction creep of wet gypsum aggregates. Journal of Geophysical Research, 102, 875-891.
\& $\&$ 1999. Influence of pore fluid salinity on pressure solution creep in gypsum. Tectonophysics, in press.

,$- \ldots$ \& PACH, C.J. 1997. Pressure solution creep in gypsum: Evidence for precipitation reaction control. Physics and Chemistry of the Earth, 22, 33-37.

Doglioni, C. 1984. Triassic diapiric structures in the central Dolomites (Northern Italy). Eclogae Geologica Helvetica, 77, 67-88.

Gill, J.S. \& Nancollas, G.H. 1980. Kinetics of growth of calcium sulphate dihydrate at heated metal surfaces. Journal of Crystal Growth, 48, 34-40.

Gould, D.B. \& De Mille, G. 1968. Piercement structures in Canadian arctic islands. American Association of Petroleum Geologists memoir, 8, 183-214.

GrigGs, D.T. 1939. Creep of rocks. Journal of Geology, 47, 225-251.

1940. Experimental flow of rocks under conditions favouring recrystallization. Geological Society of America Bulletin, 51, 1001-1022.

Heard, H.C. \& Rubey, W.W. 1966. Tectonic implications of gypsum dehydration. Geological Society of America Bulletin, 77, 741-760.

JoRDAN, P.G. 1988. Deformationsverhalten der Keuper Evaporit des BelchenTunnels (Faltenjura, Schweiz). Erlanger Geologische Abhandlungen, 116, 53-66.

1991. Development of asymmetrical shale pull-aparts in evaporite shear zones. Journal of Structural Geology, 13, 399-409.

1994. Evaporite als Abschierhorizonte: Eine gefügekundlichstrukturgeologische Untersuchung am Beispiel der Nordschweizer Trias. Beitrage zur Geologische Karte der Schweiz, 164, 1-79.

Kupfer, D.H. 1989. Gypsum dehydration, agent of salt diapirism. American Association of Petroleum Geologists Bulletin, 73, 1186.

KusHNIR, J. 1980. Effect of the $\mathrm{Ca} / \mathrm{SO}_{4}$ ratio on the growth rate and crystal habit of gypsum. In: Hsue, K.J. (ed.) International Association of Sedimentologists, 1st European meeting, Bochum, 239-241.

LeHNER, F.K. 1990. Thermodynamics of rock deformation by pressure solution. In: Barber, D.J. \& Meredith, P.D. (eds) Deformation Processes in Minerals, Ceramics and Rocks. Unwin Hyman, London, 296-333.

- 1995. A model for intergranular pressure solution in open systems. Tectonophysics, 245, 153-170.

LiU, S.T. \& Nancollas, G.H. 1970. The kinetics of crystal growth of calcium sulphate dihydrate. Journal of Crystal Growth, 6, 281-289.

\& \& 1973a. Linear crystallization and induction-period studies of the growth of calcium sulphate dihydrate crystals. Talanta, 20, 211-216.

\& \& 1973b. The crystal growth of calcium sulphate dihydrate in the presence of additives. Journal of Colloid and Interface Science, 44, 422-429.

\& 1975. A kinetic and morphological study of the seeded growth of calcium sulphate dihydrate in the presence of additives. Journal of Colloid and Interface Science, 52, 593-601.

Malavieille, J. \& Ritz, J.F. 1989. Mylonitic deformation of evaporites in décollements: examples from the Southern Alps, France. Journal of Structural Geology, 11, 583-590.

McCartney, E.R. \& Alexander, A.E. 1958. The effect of additives upon the process of crystallization. I. Journal of Colloid and Interface Science, 13, 383-396.

Murrell, S.A.F. \& IsmaIL, I.A.H. 1976. The effect of decomposition of hydrous minerals on the mechanical properties of rocks of high pressure and temperature. Tectonophysics, 31, 201-218.

NaKashima, S. 1995. Diffusivity of ions in pore water as a quantitative basis for rock deformation rate estimates. Tectonophysics, 245, 185-204.

Nancollas, G.H., Reddy, M.M. \& Tsai, F. 1973. Calcium sulphate dihydrate crystal growth in aqueous solution at elevated temperatures. Journal of Crystal Growth, 20, 125-134.

NieLSEN, A.E. 1986. Mechanisms and rate laws in electrolyte crystal growth from aqueous solution. In: DAvIS, J.A. \& HAYES, K.F. (eds) Geochemical Processes at Mineral Surfaces. ACS Symposium Series, 323, 600-614.

— \& ToFT, J.M. 1984. Electrolyte crystal growth kinetics. Journal of Crystal Growth, 67, 278-288.

Nesch, R. \& Baumann, W. 1989. Ton- und Sulfatgesteine in Wechselwirkung bei Deformation. Geologische Rundschau, 78, 443-457.

PACKTER, A. 1974. The precipitation of calcium sulphate dihydrate from aqueous solution. Journal of Crystal Growth, 21, 191-194.

PATERSON, M.S. 1995. A theory for granular flow accommodated by material transfer via an intergranular fluid. Tectonophysics, 245, 135-152.

RAJ, R. 1982. Creep in polycrystalline aggregates by matter transport through a liquid phase. Journal of Geophysical Research, 87, 4731-4739.

Robin, P.Y.F. 1978. Pressure solution at grain-to-grain contacts. Geochimica et Cosmochimica Acta, 42, 1383-1389.

RutTer, E.H. 1976. The kinetics of rock deformation by pressure solution. Philosophical Transactions of the Royal Society, London, A283, 203-219. 
1983. Pressure solution in nature, theory and experiment. Journal of the Geological Society, London, 140, 725-740.

SARIG, S. 1994. Fundamentals of aqueous solution growth. In: HurLe, D.T.J. (ed.) Handbook of Crystal Growth, 2b, Elsevier Science Publishers, Amsterdam, 1217-1269.

Shimizu, I. 1995. Kinetics of pressure solution creep in quartz: theoretical consideration. Tectonophysics, 245, 121-134.

Simón, J.L. \& Suriano, A. 1986. Diapiric deformations in the Quarternary deposits of the central Ebro Basin, Spain. Geological Magazine, 123, 45-57.

Smith, B.R. \& Alexander, A.E. 1970. The effect of additives on the process of crystallization. II. Further studies on calcium sulphate (1). Journal of Colloid and Interface Science, 34, 81-90.

Solé-Sugranes, L. 1978. Gravity and compressive nappes in the central southern Pyrenees (Spain). American Journal of Science, 278, 609-637.

Spiers, C.J. \& Brzesowsky, R.H. 1993. Densification behaviour of wet granular salt: theory versus experiment. In: Seventh Symposium on Salt, I, Elsevier Science Publishers, Amsterdam, 83-92.

— \& CARTER, N.L. 1998. Microphysics of rocksalt flow in nature. In: Aubertin, M. \& Hardy, HR. (eds) The Mechanical Behaviour of Salt: Proceedings of the Fourth Conference. Trans Technical Publications on Rock and Soil Mechanics, 22, 115-128.

— \& SChutJENS, P.M.T.M. 1990. Densification of crystalline aggregates by fluid-phase diffusional creep. In: Barber, D.J. \& Meredith, P.D. (eds) Deformation Processes in Minerals, Ceramics and Rocks. Unwin Hyman, London, 334-353.

, — - Brzesowsky, R.H., Peach, C.J., Liezenberg, J.L. \& Zwart, H.J.

1990. Experimental determination of constitutive parameters governing creep of rocksalt by pressure solution. In: KNIPE, R.J. \& RUTTER, E.H. (eds) Deformation Mechanisms, Rheology and Tectonics. Geological Society, London, Special Publications, 54, 215-227.

TAdA, R. \& Siever, R. 1989. Pressure solution during diagenesis. Annual Review of Earth Planetary Science, 17, 89-118.

- Maliva, R. \& Siever, R. 1987. A new mechanism for pressure solution in porous quartzose sandstone. Geochimica et Cosmochimica Acta, 51, 22952301.

TADRos, M.E. \& MAYES, I. 1979. Linear growth rates of calcium sulphate dihydrate crystal in the presence of additives. Journal of Colloid and Interface Science, 72, 245-254.

Underhill, J.R. 1988. Triassic evaporites and Plio-Quarternary diapirism in western Greece. Journal of the Geological Society, London, 145, 269-282.

Van Berkel, J.T., Torrance, J.G. \& Schwerdtner, W.M. 1986. Deformed anhydrite nodules: A new type of finite strain gauge in sedimentary rocks. Tectonophysics, 124, 309-323.

Van Rosmalen, G.M., Daudey, P.J. \& Marchee, W.G.J. 1981. An analysis of growth experiments of gypsum crystals in suspension. Journal of Crystal Growth, 52, 801-811.

Wall, J.R., MurRaY, G.E. \& Diaz, T.G. 1961. Geologic occurrence of intrusive gypsum and it's effect on structural forms in the Coahuila marginal folded province of northeastern Mexico. American Association of Petroleum Geologists Bulletin, 45, 1504-1522.

WeIJNEN, M.P.C. 1986. The influence of additives on the crystallization of gypsum. PhD Thesis, Technical University Delft, Netherlands.

WiLliams, S.C. 1988. The shear strength of gypsum single crystals on the three cleavage planes. Tectonophysics, 148, 163-173. 